\title{
Seeing What Is Said: Teaching Niccolò Machiavelli's Prince through Its Images
}

Khristina H. Haddad, ORCiD: 0000-0002-5937-2031

Claudia Mesa Higuera, ORCiD: 0000-0002-0566-4346

A paper presented at the American Political Science Association's Teaching and Learning Conference in Albuquerque, New Mexico, February 2020.

Presented by Khristina H. Haddad

Associate Professor and Chair of Political Science

Moravian College

Bethlehem, PA 18018

haddad@,moravian.edu

Please do not copy or distribute this paper without permission of the authors. It has been submitted for publication to PS: Politics \& Political Science and is currently under review. 


\section{Seeing What Is Said: Teaching Niccolò Machiavelli’s Prince through Its Images}

A traveler to Florence is all eyes. This city at the center of Machiavelli's political thinking is a world of architecture, sculpture, and painting. There is no choice but to embrace the visual. The student who encounters The Prince may not have walked through the streets of Florence, yet teachers of political theory can direct students to the visual aspects of his text. As a literary scholar interested in visual culture and a political theorist respectively, we propose an integration of iconographical and close textual readings. We model this multidisciplinary approach for the concepts of prudence, parsimony, liberality, and fortune by showing how the meaning of politicized concepts becomes intelligible through the study of allegorical images. We offer teachers a terminology for interpreting the text through its images. An embedded link offers access to a store of images relevant to the study of The Prince.

\section{The Art Historian's Toolkit}

The art historian Erwin Panofsky develops a methodology for the study of Renaissance art useful to teachers of political theory because it advances from simple readings to complex cultural understandings. He delineates three levels of reading an image:

1. The "primary or natural subject matter" refers to identifying an image without cultural knowledge. It constitutes the "pre-iconographical description of the work of art” (Panofsky 1982, 28). Consider Rembrandt's 1632 canvas portraying a woman riding a bull. A student narrates what she sees in terms of forms and content. This is an objective and literal process of noticing. There is no additional meaning. 
2. The "secondary or conventional subject matter" also known as "iconographical analysis" relies on access to symbolic meanings by describing and classifying conventional attributes (Panofsky 1982, 28-29). Building on the previous example, Ovid's Metamorphosis tells us that Jupiter disguised himself in the form of a white bull to seduce Europa. A white bull and a woman together stand for the abduction of Europa.

3. The "Intrinsic meaning or content" also known as "iconological interpretation" extends the analysis beyond the image by contextualizing it with regard to significant themes such as religion or politics (Panofsky 1982, 30-40). At this level, an inquiry takes place: Why did Rembrandt choose to portray the subject matter in that particular way? How are the politics of the time evident in this image? Who is the audience?

In the case of Machiavelli's text, Albert Russell Ascoli and Angela Matilde Capodivacca discuss his "dependence on a literary-iconographic tradition in his treatment of key concepts" (2010, 193). They address the multiple "figurative representations" that fill The Prince. Selecting an image is "strategic" as it has the power to "determine the direction of an argument and its conclusion" (Ascoli \& Capodivacca 2010, 193). A chosen image does not remain separate from the interpretation of the text; the image redirects and limits the interpretation (Ascoli \& Capodivacca 2010, 193).

To help students read at more critical levels, we must show them the dialogical relationship between image and text. In a text rich in historical examples, studying cultural images and the political arguments they inform offers a critical understanding of key concepts. Defining the starting point and scholarly aspirations for particular levels of reading will benefit 
students by making them conscious of hermeneutic choices and clarifying intended learning outcomes.

\section{Finding and Using Visuals}

Students often find visuals more accessible and generative starting points for class discussion.

Digital humanities resources allow instructors to find and share images with students in various media. Databases provide images that can be assigned in connection with chapters of The Prince. A selection of relevant sources and other materials is available here. Suggested discussion questions:

- What do you see depicted?

- How does a caption shift your reading of the image?

- How does an image shape your textual understanding?

- How does an image deepen conceptual understandings beyond definitions?

- Can you design a visual representation of a given concept?

Combining your chosen chapters and images, structure your lesson with the added time of reading images in mind. For another art-based approach to teaching political theory concepts, please see Tom Rozinski’s “Using Music and Lyrics to Teach Political Theory”(2015).

\section{Prudence}

Although Machiavelli does not devote a chapter to the virtue of prudence, the concept permeates the text in his insistence on the contemplation of past wisdom, alertness for present action, and care for the near future. Understood since the Middle Ages as a cardinal virtue, prudence also has 
its own visual history. We offer an emblem and a painting to help "materialize and delimit an otherwise boundless concept" (Ascoli \& Capodivacca 2010, 193).

The first image comes from Andrea Alciato's Emblemata (fig. 1). An emblem is a symbolic image followed by text. The conventional emblem—emblema triplex — has three parts:

- a motto (inscriptio),

- a symbolic image (pictura) and,

- an epigram or short prose text (subscriptio) that clarifies or expands the connection between the motto and the image. (Daly 1993, 326). 


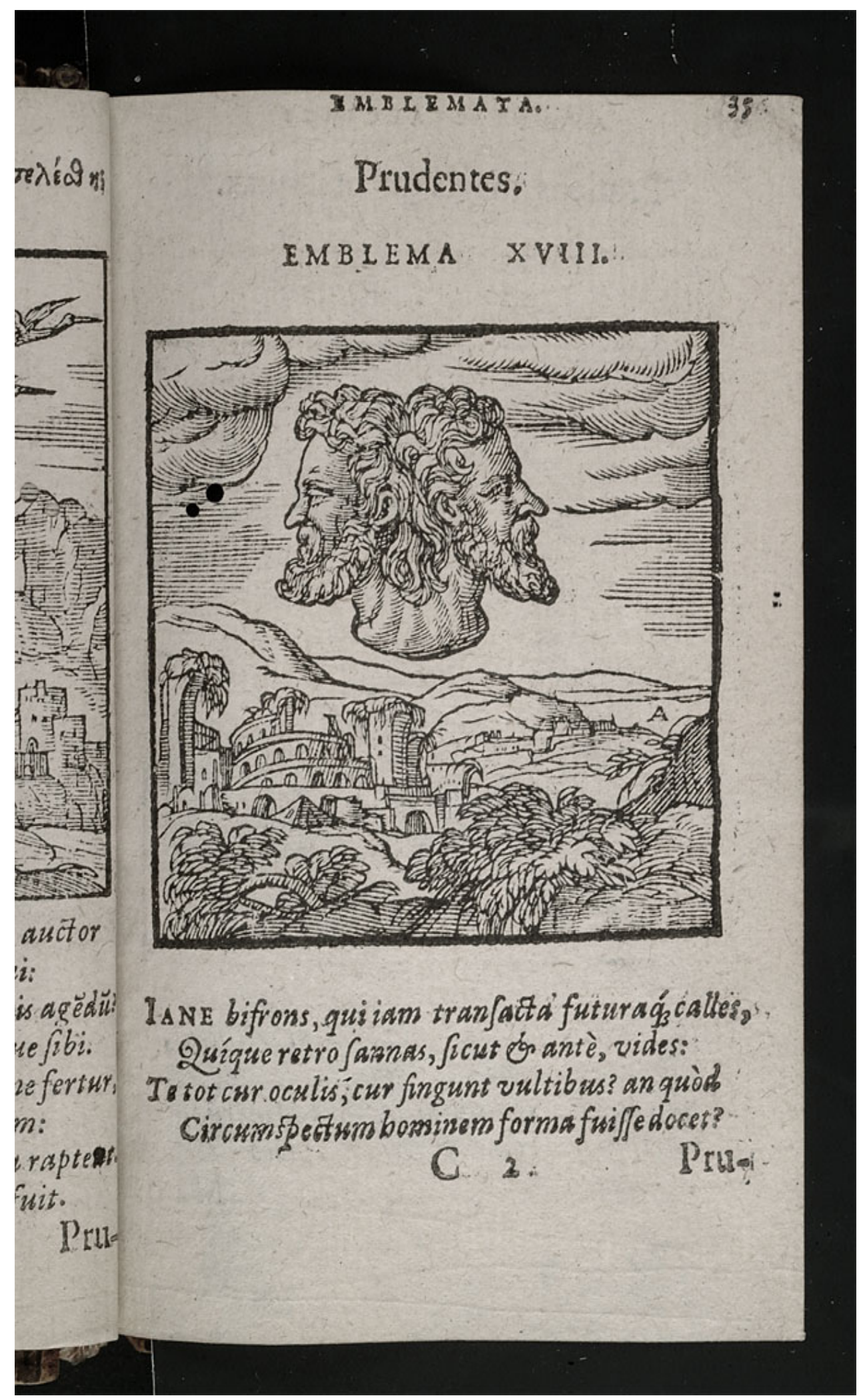

Fig. 1. Alciato, Emblem XVIII: Prudentes (Leiden, 1591) 
The Latin inscriptio accompanying the emblem XVIII reads Prudentes (The Wise).* The pictura displays Janus, the double-headed Roman god looking in two directions. The subscriptio explains the relationship between the inscriptio and the pictura: Because of his multiple perspectives, Janus is described as cautious or circumspect (Alciato 1591, 35). In classical antiquity, he is known as the guardian looking into the past and the future. Prudence demands that past knowledge translates into wise approaches to present situations and future actions.

In his dedicatory letter to Lorenzo de' Medici, Machiavelli shares his sources of political wisdom: "I have found nothing in my belongings that I care so much for and esteem so greatly as the knowledge of the actions of great men, learned by me from long experience with modern things and a continuous reading of ancient ones" (Machiavelli 1985, 3). Machiavelli's text confines this message to a particular audience, rulers. Foresight, an important part of prudence, requires looking to the horizon to assess challenges and to respond promptly when action can still be effective. He appropriates the moral commonplace of prudence for a statement on political strategy. A single-minded present orientation endangers the project of political stability: "For men are much more taken by present things than by past ones, and when they find good in the present, they enjoy it and do not seek elsewhere" (Machiavelli 1985, 96). Prudence summarizes virtù, political skill, as a kind of knowing that gives shape to the most effective action. Whereas prudence as a traditional virtue is an end in itself (moral goodness), Machiavelli repurposes prudence to elevate the imperative of achieving worldly outcomes. So, while virtuous intention might count in a moral register, political morality is judged by the visible end of action

\footnotetext{
* Translations of Alciato's Latin into English come from the transcribed pages of the Alciato at Glasgow website. Translations of Ripa's Italian into English are ours.
} 
rather than its invisible inception in consciousness. The moment of outcome is privileged over other moments.

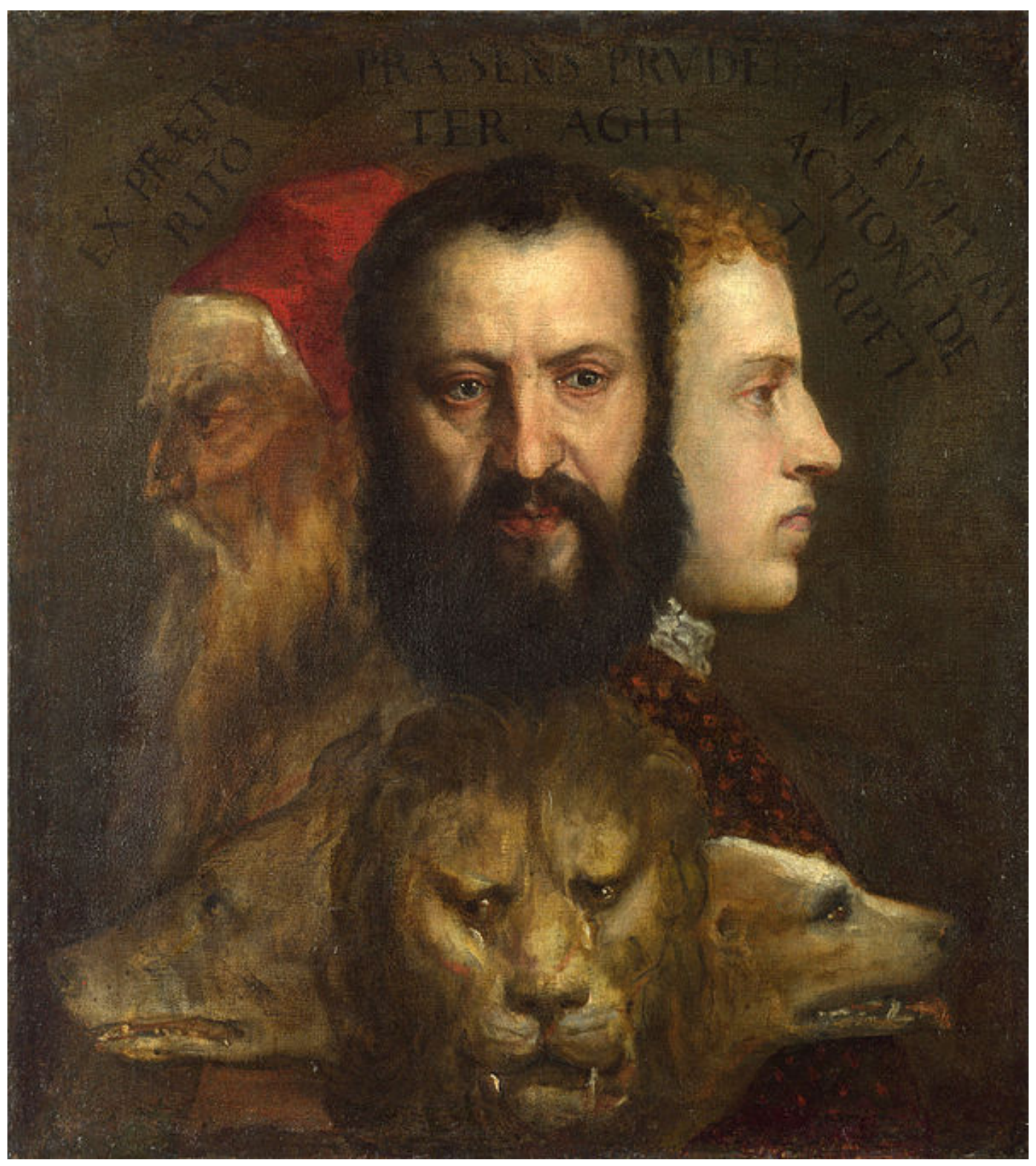

Fig. 2. Titian, An Allegory of Prudence (c. 1550-65)

A similar meditation on time can be found in Titian's An Allegory of Prudence portraying the three ages of man: youth, maturity, and old age represented by three heads (fig. 2). Old age looks to the past, maturity faces us in the present, and youth looks to life ahead, the future. A posthumously added depiction shows three animal heads - wolf, lion, and dog below the human 
heads. The animal triptych darkly echoes the faces above. In the background, a Latin inscription is faintly legible: EX PRAETERITO/ PRAESENS PRVDENTER AGIT / NI FVTVR $\bar{A} A C T I O N \bar{E}$ DE DETVRPET (From the past/ the present acts prudently/ lest it spoil future action). The painting shows consciousness directed at different moments. The three tenses and their potentially simultaneous urgency highlight the mental demands of effective leadership: a ruler cannot afford just one focus. This is a psychic portrait of an autarch unbounded by a singular way of thinking. The exceptional leader single-handedly masters what it usually takes several to accomplish.

Titian's painting asserts the integration of human and animal natures. Famously, Machiavelli advocates for combining the powers of the lion and the fox thereby emphasizing the importance of action informed by both physical prowess and cunning: "Thus, since a prince is compelled of necessity to know well how to use the beast, he should pick the fox and the lion, because the lion does not defend itself from snares and the fox does not defend itself from wolves. So one needs to be a fox to recognize snares and a lion to frighten the wolves" (Machiavelli 1985, 69). Similarly, in Chapter XVIII "In What Mode Faith Should be Kept by Princes," Machiavelli stresses inner plurality as the necessary condition of leadership. By contrast with the singular identity of the Platonic soul, he symbolically expresses this plurality of the psyche in a hybrid being combining multiple natures.

Liberality and Parsimony 
In Chapter XVI “Of Liberality and Parsimony,” Machiavelli offers a counterintuitive account of the political merits of these two virtues. Liberality enjoys a good reputation, but parsimony

proves to be the more successful strategy over time in political practice:

Thus, since a prince cannot, without damage to himself, use the virtue of liberality so that it is recognized, he should not, if he is prudent, care about a name for meanness. For with time, he will always be held more and more liberal when it is seen that with his parsimony his income is enough for him, that he can defend himself from whoever makes war on him, and that he can undertake campaigns without burdening the people. (Machiavelli 1985, 63)

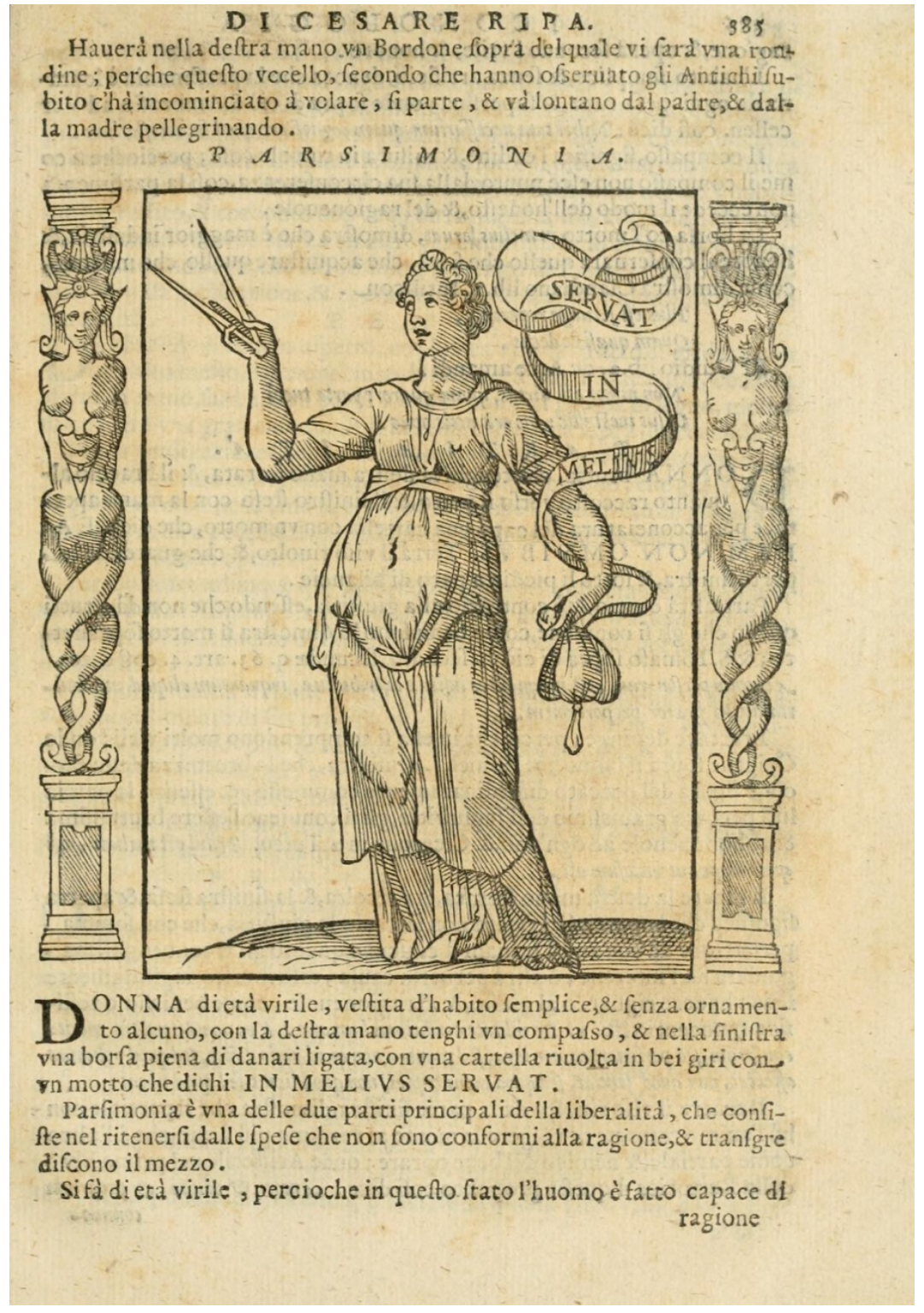

Fig. 3. Ripa, "Parsimonia.” Iconologia (1603) 
Visual representations of this concept can be found in Ripa's 1603 edition of Iconologia (fig. 3). There, parsimony is represented as a mature woman dressed in plain clothes. In her right hand, she holds a compass, and in the left, a closed bag full of money. A banderole reads: In melius servat (May the better one serve). The woman looks to the right, indicating her choice: parsimony will best serve her ends (Ripa 1603, 385). Yet, in the 1613 edition of Iconologia, the woman's gaze is frontal, favoring neither attribute. No decision has been made. Questions arise: Which is better? Liberality (the bag of money) or parsimony (the compass)? Which will serve best? A small shift in the visual representation, the neutrality of the gaze favoring neither side, yields a more open-ended lesson. The text clarifies the message: Ripa states that liberality is a violation of measurement: "It is to your advantage to have parsimony because in order to grow your income you need to moderate your expenses" (Ripa 1603, 385). By being parsimonious, you gain liberality, a message well-known to readers of Machiavelli. Parsimony enables selfsufficiency and allows one to acquire a politically desirable reputation for liberality.

Symbolized by the compass, measurement is the shared attribute of both parsimony and liberality. Ripa's personification of liberality shows a woman in white robes and a spread eagle crowning her head (fig. 4). She holds two cornucopias. One shows durable riches, including a crown, falling to the floor. The other one displays the perishable abundance of nature. As in the representation of parsimony, the compass appears on the right. It is an instrument that does not leave its circumference in the sense that the parsimonious does not exceed the honest and reasonable (Ripa 1603, 386). Not exceeding limits defines both liberality and parsimony. Liberality is not giving with abandon but requires prudence just as parsimony does. 
Machiavelli's argument in The Prince restates this guideline in the context of political action: neither too little nor too much but just the right amount. He fears that excessive spending compels future taxation or even confiscation of private property, practices that engender hatred. He argues that the ingratitude of others and growing expectations over time erode the wealth of the liberal ruler who must constantly give more to preserve the good will of his subjects. Better to start off by being measured and to retain the ability to give in the long run. This strategy allows for perceived generosity and enhances political legitimacy because it preserves resources and reputation. Although it may seem to be an advantage "to be held liberal," Machiavelli recommends parsimony as a more reliable path to loyalty and power (Machiavelli 1982, 64-65). 


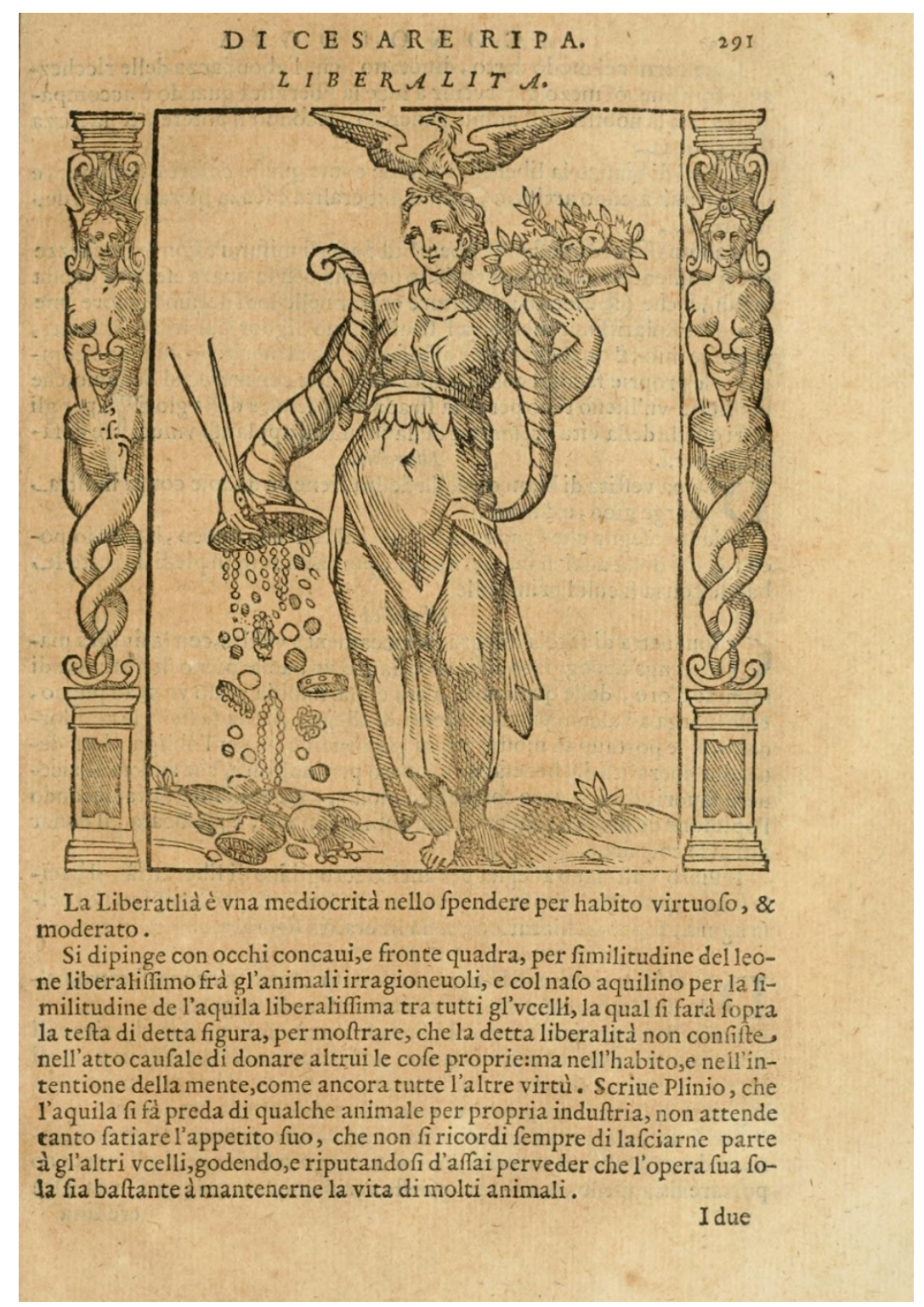

Fig. 4. Liberality (Ripa’s Iconologia, 1603)

Looking at the images for parsimony and liberality above, we see the commonplace meanings already in circulation at the time The Prince was written. The images are prior to the text, the visual culture that is the precondition of Machiavelli's argument. The revaluation of values in the case of parsimony and liberality comes to him through a well-established iconographic tradition codified in Ripa's text, a manual consulted by orators, painters, and poets who want to personify not only virtues and vices but also the arts, sciences, and abstract 
concepts. Thus, Machiavelli's representations are consistent with a systematized visual approach to cultural concepts, an established code.

\section{Fortuna and Impetuosity}

To order the world is to anticipate the potential impact of the unexpected in the form of storms, floods, and illnesses. Nature and the actions of others set the pace for politics. In Chapter XXV, "How Much Fortune Can Do in Human Affairs, and in What Mode It May be Opposed," Machiavelli demands agency through constant adjustment to the imperatives of the moment after acknowledging conventional wisdom on the futility of action:

It is not unknown to me that many have held and hold the opinion that worldly things are so governed by fortune and by God, that men cannot correct them with their prudence, indeed that they have no remedy at all; and on account of this they might judge that one need not sweat much over things but let oneself be governed by chance. (Machiavelli 1982, 98)

Moving his lip service to a fatalistic worldview, he displaces the divine in favor of fortune and free will: "Nonetheless, in order that our free will not be eliminated, I judge that it might be true that fortune is arbiter of half of our actions, but also that she leaves the other half, or close to it, for us to govern" (Machiavelli 1982, 98).

Alciato’s emblem XCVIII Ars naturam adiuvans (Art assisting nature) illustrates Machiavelli's understanding of the instability of fortune contrasted with the ability of art (technê) to stabilize nature (fig. 5). Hermes, the messenger of the gods in charge of communications, sits on a square pedestal and holds the caduceus. He reaches out to Fortuna balancing blindfolded on a sphere. A billowing sail threatens her equilibrium. The emblem epigram reads: "Art [represented by Hermes] was developed to counteract the effect of Fortune, but when Fortune is 
bad, it often needs the assistance of Art. Therefore, studious youths learn good arts, which bring with them the benefits of an outcome not subject to chance" (Alciato 1591, 119).

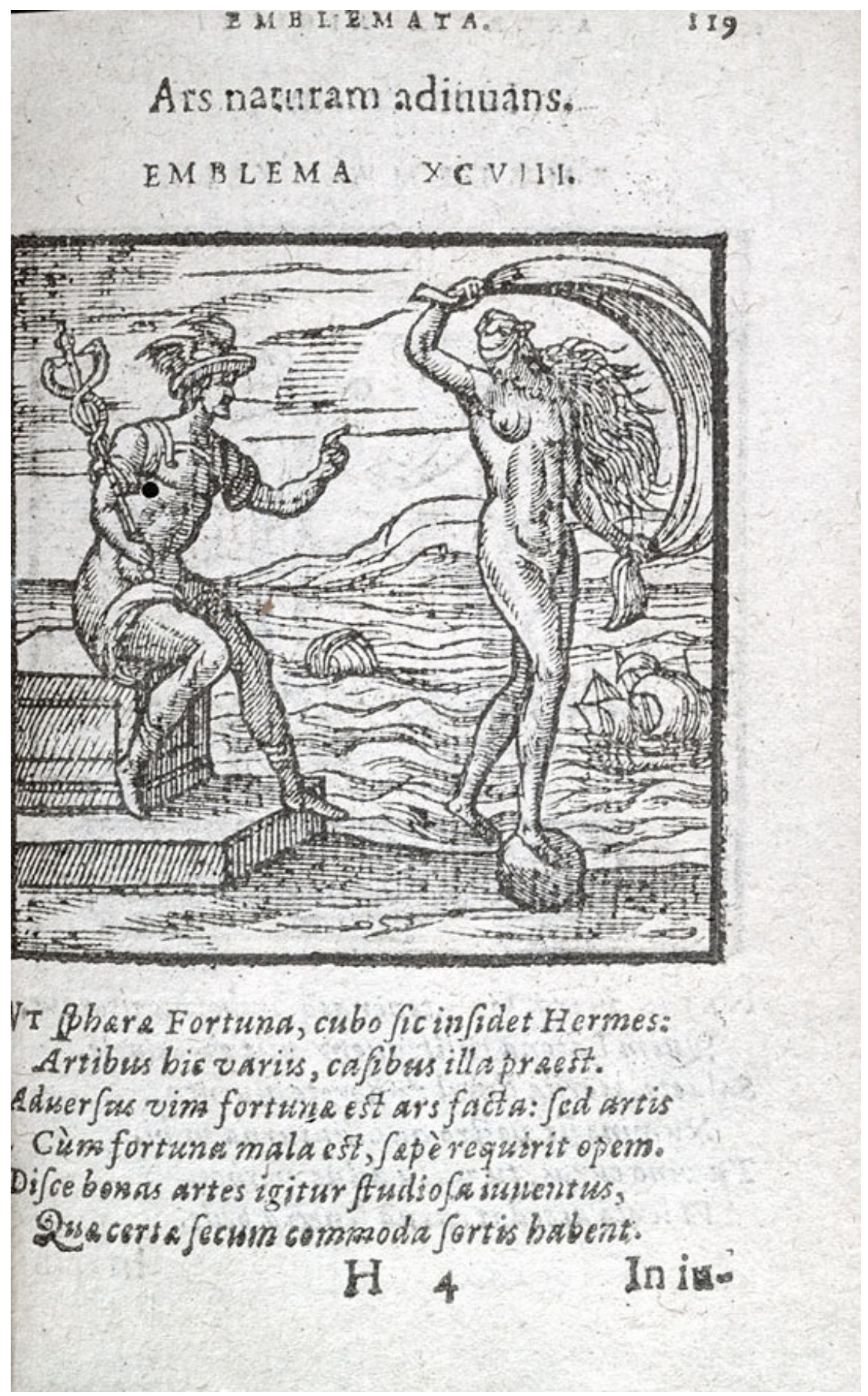

Fig. 5. Alciato's Emblem XCVIII: Ars naturam adiuvans (Leiden, 1591) 
Alciato's emblem XCVIII Ars naturam adiuvans (Art assisting nature) illustrates

Machiavelli's understanding of the instability of fortune contrasted with the ability of art (technê) to stabilize nature (fig. 5). Hermes, the messenger of the gods in charge of communications, sits on a square pedestal and holds the caduceus. He reaches out to Fortuna balancing blindfolded on a sphere. A billowing sail threatens her equilibrium. The emblem epigram reads: "Art [represented by Hermes] was developed to counteract the effect of Fortune, but when Fortune is bad, it often needs the assistance of Art. Therefore, studious youths learn good arts, which bring with them the benefits of an outcome not subject to chance" (Alciato 1591, 119).

Machiavelli deploys metaphors to convey practical political lessons. His invocation of Fortuna highlights the importance of agency: the natural world requires an artful approach. Precautions must be taken in advance of natural catastrophes: "And I liken her to one of these violent rivers which, when they become enraged, flood the plains, ruin the trees, ... it is not as if men, when times are quiet, could not provide for them with dikes and dams so that when they rise later, either they go by a canal or their impetus is neither so wanton nor so damaging" (Machiavelli 1984, 98). Fortune needs skillful taming. This is a theory of moral action applied to politics: one must act in anticipation of problems to protect order: "It happens similarly with fortune, which shows her power where virtue has not been put in order to resist her" (Machiavelli 1984, 98).

Contrast the first representation of Fortuna as a student tutored by Hermes with an engraving in Charles de Bouelles's Liber de Intellectu showing Fortuna and Sapientia sitting across from each other (fig. 6). They appear to be equals. Blindfolded, Fortuna sits on a sphere inscribed Sedes Fortune Rotunda. Holding her wheel, she balances on an inclined plane teetering 
on a fulcrum. She is not well-grounded, yet she rules the world. Her strength derives from imbalance and unpredictability.

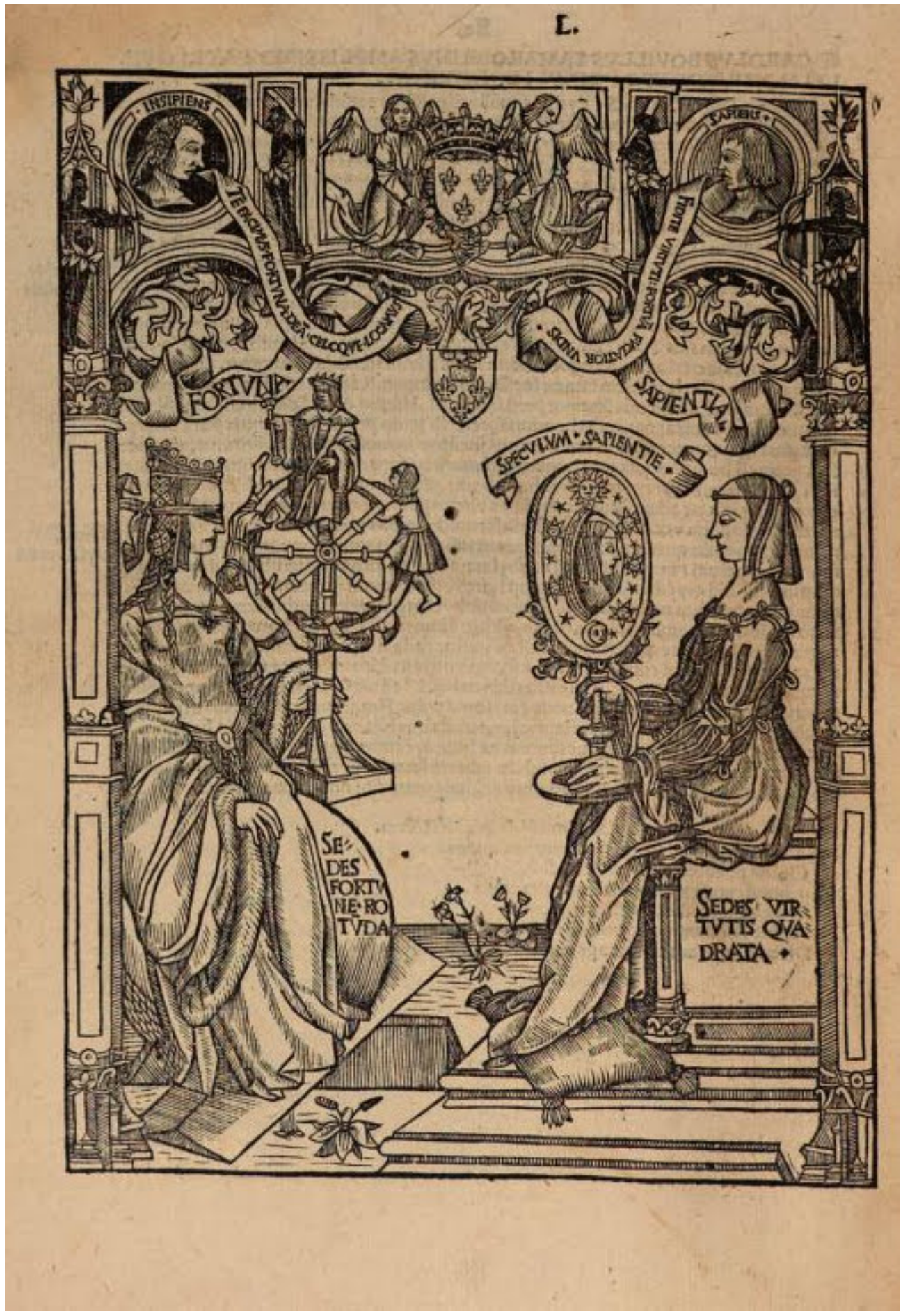

Fig. 6. Charles de Bouelles, Liber de Intellectu (Paris, 1510) 
Across from Fortuna, Sapientia holds the mirror of self-knowledge, speculum sapientie. Her wisdom encompasses both self and world signified by the mirror's margins depicting the heavenly bodies. This statement dovetails with Machiavelli's lesson: a ruler cannot divert his attention from worldly matters or afford apolitical self-centeredness. Sapientia rests on a stable square foundation with the inscription: Sedes virtutis quadrata. The legend on Sapientia's throne reads Virtutis, the genitive singular of virtus meaning variously manliness, courage, and resoluteness. Overhead, a second dialogue is visible: above Fortuna, the fool INSIPIENS proclaims: Te facimus Fortuna deam celoque locamus (We make you, Fortune, a goddess and we elevate you to heaven). Above Sapientia, the wise man SAPIENS announces: Fidite virtuti: Fortunam fugatior undis (Trust in virtue: Fortune is more fleeting than waves).

What insights are yielded by comparing these two personifications of fortune? In Alciato's emblem on art assisting nature, Hermes (art) aids Fortuna (nature). In comparison, in Bouelles's frontispiece, Sapientia and Fortuna might well be peers. They are not in conflict with each other; each has her place. The embedded text, however, makes them unequal, aligning Fortuna with the fool and Sapientia with the wise man. These are two conventional representations of Fortuna that show the possibility of variation and its implications for understanding an abstract concept.

These varying but standard representations of Fortuna stand in stark contrast with Machiavelli's sexual and violent attitude towards the goddess. Studying fortune, we see that audacity and impetuosity are the final lessons in the Machiavellian arsenal:

I conclude, thus, that when fortune varies and men remain obstinate in their modes, men are prosperous while they are in accord, as they come into discord, unprosperous. ... it is better to be impetuous than cautious, because fortune is a woman; and it is necessary, if one wants to hold her down, to beat her and strike her down. And one sees that she lets herself be won more by the 
impetuous than by those who proceed coldly. And so always like a woman, she is the friend of the young, because they are less cautious, more ferocious, and command her with more audacity. (Machiavelli 1984, 101)

Here, Machiavelli offers his dramatic representation of masculine physical, even sexual, readiness, and combative power. He embraces impetuosity to conquer fortuna. Consider a competing representation of those qualities as they appear in Ripa's account of impetus as a youthful and virile raw force:

A young and valiant man of fierce demeanor who should appear barely clothed in the moment of impetuously confronting an enemy. So that at the moment of unsheathing his sword, he will appear as if he were thrusting. He appears blindfolded and with wings on his shoulders accompanied by an equally furious wild boar foaming at the snout, in the same demeanor as the person trying to attack. (Ripa 1613, 390)

In Ripa's ekphrastic description, impetus is personified as a potent young man. Unlike

Machiavelli, Ripa does not praise youthful impetuosity: impetus is a failure not an aspirational quality. Like a rabid animal, it is a raw force devoid of the prudence present in Machiavelli's earlier lessons on virtù. Machiavellian impetus is virtù unleashed in the moment of crisis. The lack of deliberation is evident in this personification for the youth appears "deprived of the light of the intellect that is the rule and measurement of all human actions" (Ripa 1613, 390).

Machiavelli embraces impetuosity as a means to an end. Impetus must be excessive and forceful as it must respond to an extreme situation. While the story reads as one of brutal misogynistic violence, the message about impetus may be that an effort beyond all imagination and every rule is sometimes necessary for rulers.

\section{Into the Classroom}

As a political theorist, Machiavelli's work consists in unsettling and redirecting conventional meanings. We can understand how he accomplishes this by attending to the codified culture of 
Renaissance art. As teachers, we ask students to lean out of their time and space to understand The Prince beyond seemingly self-evident contemporary meanings. We ask them to look into the text as a dialogue between the author and a set of commonplaces. By teaching students about cultural conventions of the time, we can show them how Machiavelli strategically reworks familiar codes in the service of his political argumentation. Recognizing the codified culture of the Renaissance challenges our hermeneutics. 


\section{Works Cited}

Alciato, Andrea. 1591. Emblemata. Leyden, Officina Plantiniana. Alciato at Glasgow: Home, https://www.emblems.arts.gla.ac.uk/alciato/books.php?id=A91a

Ascoli, Albert Russell \& Angela Matilde Capodivacca. 2010. "Machiavelli and poetry.” In John M. Najemy (ed.), The Cambridge Companion to Machiavelli. Cambridge: Cambridge University Press. 190-205.

Bouelles, Charles de. 1510. Liber de Intellectu. Parisiis: Stephanus \& Parvus. Düsseldorf: Universitäts- und Landesbibliothek, 2011. http://digital.ub.uni-duesseldorf.de/ihd/content/titleinfo/1257157.

Daly, Peter M. 1993. "Emblem.” The New Princeton Encyclopedia of Poetry and Poetics. Eds.

Alex Preminger and T.V.F. Brogan. Princeton: Princeton UP, 1993.

Machiavelli, Niccolò. 1985. The Prince. Trans. Harvey C. Mansfield. Chicago: The University of Chicago Press.

Panofsky, Erwin. 1982. "Iconography and Iconology: An Introduction to the Study of Renaissance Art.” In Meaning in the Visual Arts. Chicago: The University of Chicago Press. 26-54.

Ripa, Cesare. 1603. Iconologia. Roma: Appresso Lepido Facij. The Internet Archive, https://archive.org/details/iconologiaouerod00ripa/page/n4

---. 1613. Siena, Matteo Florimi. The Internet Archive, https://archive.org/details/iconologiadicesa02ripa/page/134

Rozinski, Tom. 2015. "Using Music and Lyrics to Teach Political Theory.” PS: Politics and Political Science. 48 (3): 483- 87. 
Vecellio, Tiziano. ca. 1550-65. An Allegory of Prudence, oil on canvas, 75.5 x $68.4 \mathrm{~cm}$. London: The National Gallery. 